\title{
Características bromatológicas e terapêuticas da farinha de resíduos de abóbora:
}

\section{Revisão sistemática}

\author{
Bromatological and therapeutic characteristics of pumpkin waste flour: Deep review \\ Caracteristicas bromatológicas y terapéuticas de la harina de residuos de calabaza: Revisión
} sistemática

Recebido: 10/03/2021 | Revisado: 15/03/2021 | Aceito: 25/03/2021 | Publicado: 02/04/2021

Kellen Cristina Masaro Carvalho
ORCID: https://orcid.org/0000-0003-4484-1111
Instituto Federal de Educação, Ciência e Tecnologia do Sul de Minas Gerais, Brasil
E-mail: kellen.carvalho@ifsuldeminas.edu.br
Aline Manke Nachtigall
ORCID: https://orcid.org/0000-0002-9691-0361
E-mail: aline.manke@ifsuldeminas.edu.br
José Antonio Dias Garcia
Instituto Federal de Educação, Ciência e Tecnologia do Sul de Minas Gerais, Brasil
ORCID: https://orcid.org/0000-0002-4024-3045
Instituto Federal de Educação, Ciência e Tecnologia do Sul de Minas Gerais, Brasil
Universidade José do Rosário Vellano, Brasil
E-mail: jadiasgarcia@gmail.com
Andressa Santanna Natel
ORCID: https://orcid.org/0000-0002-8252-1090
Universidade José do Rosário Vellano, Brasil
E-mail: andressa.natel@unifenas.br

\begin{abstract}
Resumo
Entre os alimentos desperdiçados estão as cascas e as sementes de abóbora, que podem ser transformadas em farinha para uso alternativo como fonte de nutrientes. O objetivo deste trabalho foi realizar uma revisão sistemática sobre estudos, indexados nos últimos 10 anos (2011 a 2020), envolvendo as características bromatológicas e terapêuticas de farinhas contendo resíduos de abóbora (Cucurbita moschata) para uso na alimentação. Para isso, foram selecionadas 4 bases de dados (BVS-LILACS, CAPES, Google Acadêmico e SciELO) utilizando os termos "antinutrientes de cucurbitas", "nutrição cucurbitaceae", "benefícios de C. moschata", "resíduo de Cucurbita moschata", "resíduos de abóbora", "farinha de abóbora", "subprodutos de abóbora", "coprodutos da abóbora", "casca de abóbora" e "semente de abóbora". Os resultados indicaram que a farinha de resíduos de abóbora constitui-se boa fonte de lipídios, fibras, proteínas, minerais e agentes antioxidantes. Conclui-se que a farinha de resíduos de abóbora pode ser incluída na alimentação humana e animal como fonte funcional e nutricional, porém é indicado estudos para comprovar seus efeitos terapêuticos.
\end{abstract}

Palavras-chave: Casca; Cucurbita moschata; Nutrição; Produtos farináceos; Semente.

\begin{abstract}
Among the food waste are pumpkin peels and seeds, which can be turned into flour for alternative use as a source of nutrients. The objective of this work was to carry out a deep review of studies, indexed in the last 10 years (2011 to 2020), involving the bromatological and therapeutic characteristics of flours containing pumpkin residues (Cucurbita moschata) for use in food. For that, 4 databases were selected (BVS-LILACS, CAPES, Google Scholar and SciELO) using the terms "antinutrients of Cucurbites", "nutrition Cucurbitaceae", "benefits of C. moschata", "residue of Cucurbita Moschata", "pumpkin waste", "pumpkin flour", "pumpkin by-products", "pumpkin co-products", "pumpkin peel" and "pumpkin seed". The results indicated that pumpkin waste flour is a good source of lipids, fibers, proteins, minerals, and antioxidants. It is concluded that pumpkin waste flour can be included in human and animal food as a functional and nutritional source, however studies are indicated to prove its therapeutic effects.
\end{abstract}

Keywords: Peel; Cucurbita moschata; Nutrition; Flour products; Seed.

\section{Resumen}

Entre los alimentos desperdiciados están las cáscaras y las semillas de calabaza, que pueden ser transformadas en harina para uso alternativo como fuente de nutrientes. El objetivo de este trabajo fue realizar una revisión sistemática sobre estudios, indexados en los últimos 10 años (2011 a 2020), que involucran las caracteristicas bromatológicas y terapéuticas de harinas que contienen residuos de calabaza (Cucurbita moschata) para su uso en la alimentación. Con 
ese objetivo, se seleccionaron 4 bases de datos (BVS-LILACS, CAPES, Google Académico y SciELO) y utilizaron los términos "anti nutrientes de cucurbitas", "nutrición cucurbitaceae", "beneficios de C. moschata", "residuo de Cucurbita moschata", "residuos de calabaza", "harina de calabaza", "subproductos de calabaza", "coproductos de calabaza", "cáscara de calabaza" y "semilla de calabaza". Los resultados indicaron que la harina de residuos de calabaza se constituye en buena fuente de lípidos, fibras, proteínas, minerales y agentes antioxidantes. Se concluye que la harina de residuos de calabaza puede ser incluida en la alimentación humana y animal como fuente funcional y nutricional, sin embargo están indicados estudios que prueben sus efectos terapéuticos.

Palabras clave: Cáscara; Cucurbita moschata; Nutrición; Productos harinosos; Semilla.

\section{Introdução}

No Brasil, por ano, estima-se que 26 milhões de toneladas de resíduos sólidos são desperdiçados (Benítez, 2019), dentre esses desperdícios estão os resíduos resultantes do processamento de hortaliças que podem causar sérios problemas ambientais se não forem tratados, além de representarem perdas significativas de nutrientes.

Entre as hortaliças utilizadas na agroindústria está a abóbora, que possui partes não convencionais como cascas e sementes. A abóbora da espécie Cucurbita moschata é uma das mais cultivadas no Brasil, sendo sua semente caracterizada pelo efeito antimicrobiano, hipoglicêmico, anticancerígeno, antioxidante, anti-inflamatório, vermífugo (Matthewsa et al., 2016) e também pela presença de compostos bioativos como lipídios, proteínas, polissacarídeos, fitoesteróis, vitaminas e minerais (Maldonade et al., 2019). Já a casca, constitui significativa fonte de proteínas, fibras (Kim et al., 2012); vitamina A e vitamina C (Fioroto et al., 2019).

Uma alternativa viável para o aproveitamento de resíduos, constitui-se na elaboração de farinhas, sendo o processo de secagem dos resíduos, a etapa caracterizada pela conservação do potencial nutritivo, redução da perecibilidade (Araújo et al., 2017) e eliminação dos fatores antinutricionais (Vale et al., 2019).

Portanto, o aproveitamento dos resíduos da abóbora e sua transformação em farinha é uma estratégia que contribui com a redução no desperdício de alimentos e uma opção que agrega valor nutricional na criação de novas receitas.

Nesta perspectiva, o objetivo desse trabalho foi realizar uma revisão sistemática sobre estudos envolvendo as características bromatológicas e terapêuticas de farinhas contendo resíduos de abóbora (Cucurbita moschata) para uso na alimentação.

\section{Metodologia}

O presente trabalho consistiu em uma revisão sistemática elaborada no período de setembro de 2020 a dezembro de 2020, fundamentada a partir de artigos científicos nacionais relacionados com as características bromatológicas e terapêuticas de farinhas contendo resíduos de abóbora para uso na alimentação, indexados nos últimos 10 anos (2011 a 2020).

A pesquisa foi realizada nas bases de dados: BVS-LILACS (https://lilacs.bvsalud.org/); CAPES (http://wwwperiodicos-capes-gov-br.ezl.periodicos.capes.gov.br/index.php?); Google Acadêmico (https://scholar.google.com.br/?hl=pt) e SciELO (https://scielo.org/). As buscas nas fontes supracitadas foram realizadas tendo como termos indexadores na língua portuguesa: "antinutrientes de cucurbitas", "nutrição cucurbitaceae", "benefícios de C. moschata", "resíduo de Cucurbita moschata", "resíduos de abóbora", "farinha de abóbora", "subprodutos de abóbora", "coprodutos da abóbora”, "casca de abóbora" e "semente de abóbora".

Após as buscas bibliográficas, os critérios de inclusão e exclusão foram aderidos às diretrizes de revisão sistemática (Moher et al., 2015). Os estudos elegíveis foram incluídos se cumprissem, os seguintes critérios: artigos científicos completos publicados em revistas com a temática de características bromatológicas e terapêuticas de farinhas contendo resíduos de abóbora pertencentes à espécie Cucurbita moschata para uso na alimentação; realizadas no Brasil e no idioma português. Os estudos foram excluídos com base nos seguintes critérios: trabalho de conclusão de curso, monografia, dissertação de 
mestrado, tese de doutorado, resumo expandido em anais de eventos, capítulos de livro, relatórios de estágio e artigos de revisão. Cada estudo foi avaliado de forma independente para inclusão por dois investigadores, e as discrepâncias foram resolvidas por discussão. Os trabalhos repetidos em diferentes bases de dados foram excluídos.

Os dados foram recuperados dos estudos e organizados em tabelas segundo o título, os autores, o local de realização da pesquisa, ano de publicação e principais resultados das características bromatológicas e terapêuticas.

O presente estudo foi baseado em literaturas já publicadas, portanto, não foi necessária a aprovação pelo Comitê de Ética.

\section{Resultados e Discussão}

A presente revisão forneceu inicialmente 849 resultados, sendo 16 resultados encontrados com o termo "resíduos de abóbora"; 44 resultados encontrados com o termo "farinha de abóbora"; 5 resultados encontrados com o termo "subprodutos de abóbora"; 19 resultados encontrados com o termo "coprodutos da abóbora"; 122 resultados encontrados com o termo "casca de abóbora" e 643 resultados encontrados com o termo "semente de abóbora" (Figura 1). Os termos indexadores: "antinutrientes de cucurbitas"; "nutrição cucurbitaceae"; "benefícios de C. moschata" e "resíduo de cucurbita moschata" não apresentaram resultados nas bases de dados pesquisadas.

Os resultados iniciais das buscas por artigos científicos nacionais contendo as características bromatológicas e terapêuticas de farinhas contendo resíduos de abóbora (Cucurbita moschata) para uso na alimentação, nas bases de dados e fontes supracitadas indexados nos últimos 10 anos (2011 a 2020) encontram-se na Figura 1.

Figura 1. Representação dos resultados iniciais, por termo indexador, nas bases de dados (BVS-LILACS, CAPES, Google Acadêmico e SciELO) no período de 2011 a 2020.

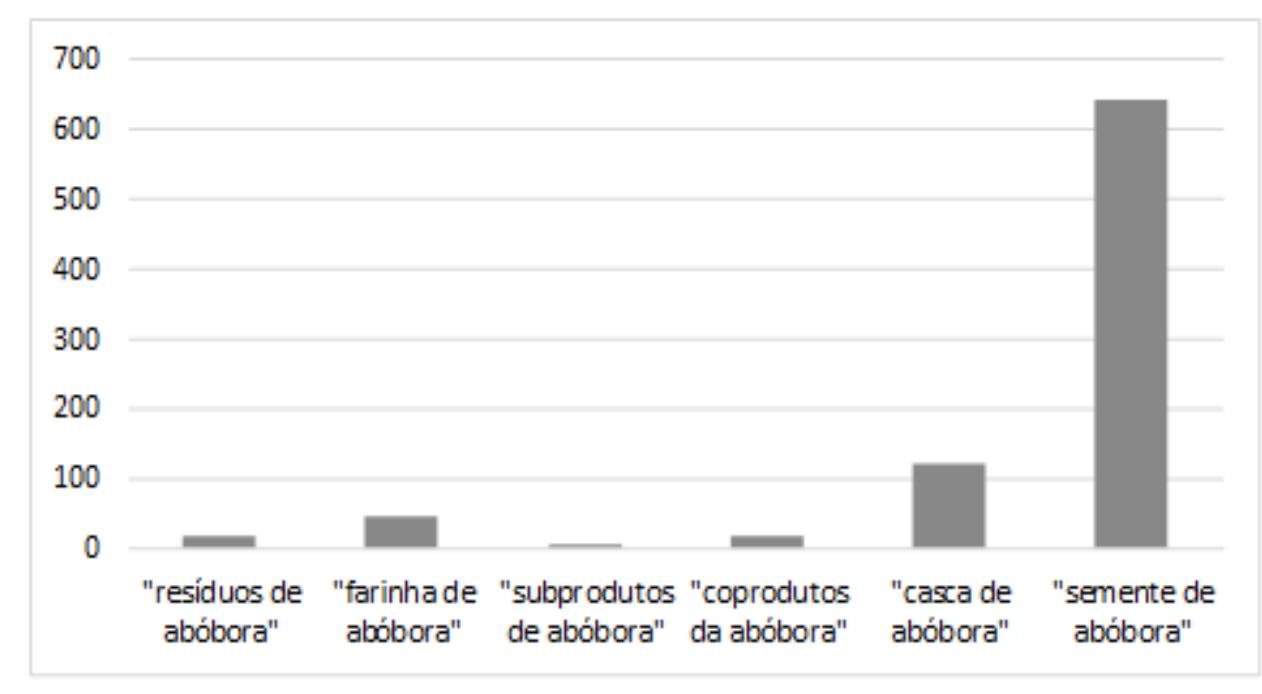

Fonte: Autores.

Após a aplicação dos critérios de inclusão e exclusão, o material empírico desta revisão sistemática ficou composto por 4 artigos científicos, categorizados quanto ao título, ano de publicação, autores, local de realização da pesquisa e tipo de característica avaliada, conforme a Tabela 1. 
Tabela 1. Categorização dos artigos científicos de língua portuguesa realizados no Brasil no período de 2011 a 2020 e que contemplam as características bromatológicas e terapêuticas de farinhas contendo resíduos de abóbora (Cucurbita moschata).

\begin{tabular}{|c|c|c|c|c|}
\hline Título & $\begin{array}{c}\text { Ano de } \\
\text { Publicação }\end{array}$ & Autores & Local da Pesquisa & $\begin{array}{c}\text { Tipo de } \\
\text { característica }\end{array}$ \\
\hline $\begin{array}{l}\text { Desenvolvimento e aceitação de pães sem } \\
\text { glúten com farinhas de resíduos de abóbora } \\
\text { (Cucurbita moschata })\end{array}$ & 2017 & Anjos et al. & Petrolina - PE & Bromatológica \\
\hline $\begin{array}{c}\text { Potencial uso de sementes de abóbora } \\
\text { (Cucurbita moschata) como aproveitamento } \\
\text { de resíduo }\end{array}$ & 2019 & Severino et al. & $\begin{array}{l}\text { São José do Rio Preto } \\
-\mathrm{SP}\end{array}$ & Bromatológica \\
\hline $\begin{array}{l}\text { Potencial anti-helmíntico de sementes de } \\
\text { abóbora (Cucurbita moschata) em equinos }\end{array}$ & 2020 & Lima et al. & Ceres - GO & Terapêutica \\
\hline $\begin{array}{l}\text { Caracterização física e química de farinha } \\
\text { de arroz, farinhas de cascas de abacaxi e } \\
\text { banana e farinhas de sementes de abóbora }\end{array}$ & 2020 & Fortes et al. & Machado-MG & Bromatológica \\
\hline
\end{tabular}

Fonte: Autores (2021).

No que se refere aos principais resultados das características bromatológicas obtidos pelos autores (Tabela 2), Anjos et al. (2017) verificaram que a farinha de casca de abóbora (FCA) apresentou maiores teores de umidade (7,95\%), cinzas $(8,89 \%)$ e carboidratos totais $(67,68 \%)$, enquanto a farinha de semente de abóbora (FSA) apresentou maiores teores de lipídios $(35,95 \%)$, proteínas $(32,20 \%)$, fibras $(20,31 \%)$ e calorias $(520,70 \mathrm{kcal} / 100 \mathrm{~g})$, assim, concluíram que a farinha de casca e semente de abóbora mostram-se como boa alternativa para uso em preparações, pois proporciona um produto mais rico nutricionalmente resultante dos valores de cinzas, lipídios, proteínas e fibras.

Severino et al. (2019) avaliaram a composição centesimal da FSA, que apresentou quantidades importantes de nutrientes necessários para a dieta humana, como lipídios, proteínas e carboidratos. A elevada quantidade de lipídios (35,82\%) indicou que a FSA é uma boa fonte de óleo. Quanto a composição de proteínas (33,94\%), sugeriram que essas sementes podem ser utilizadas como fornecedora de proteínas e ingrediente para o enriquecimento de novos produtos e quanto a quantidade de cinzas $(4,26 \%)$, concluíram que a FSA é rica em micronutrientes. Já aos carboidratos $(19,26 \%)$ e valor calórico $(535,18$ $\mathrm{kcal} / 100 \mathrm{~g}$ ), os valores obtidos foram considerados significativos (Tabela 2).

A FSA avaliada por Fortes et al. (2020) apresentou fenólicos totais de 963,11 mg de equivalente de ácido gálico/g, atividade antioxidante de 14.970,33 $\mu$ mol de equivalente de Trolox/g e índice antioxidante de fenólicos (PAOXI) igual a 15,55. Esses resultados indicam que os compostos fenólicos presentes na FSA possuem grande potencial para captura de elétrons. Os resultados também mostraram ausência de atividade de inibição a tripsina, sendo assim, os autores consideraram a FSA uma boa alternativa para aplicação em produtos de panificação, pois determina um produto mais rico nutricionalmente, resultante do aumento nos teores de lipídios (35,13\%) e fibras insolúveis $(21,84 \%)$, além de ser uma opção viável para implementação desse nutriente na dieta livre de glúten. Em relação a cor, observaram que a FSA apresentou uma coloração clara $\left(\mathrm{L}^{*}=59,49\right)$, uma vez que o zero corresponde ao preto e o cem ao branco. Os valores obtidos para os parâmetros a* $(-$ verde/vermelho+) e b* (-azul/amarelo+) indicaram que a FSA mostrou-se avermelhada $\left(a^{*}=3,47\right)$ e amarela $\left(b^{*}=27,83\right)$. O parâmetro croma que refere-se a intensidade da cor, que aumenta a partir de zero conforme aumenta os valores de $\mathrm{a}^{*} \mathrm{e} \mathrm{b}^{*}$ indicou que a FSA possui cor desejável para alimentos (croma $=28,04$ ) e o ângulo Hue que caracteriza diferentes tonalidades 
de cor $\left(0^{\circ}=\right.$ cor vermelha; $90^{\circ}$ cor amarelo, $180^{\circ}$ verde e $270^{\circ}$ azul $)$ indicou que a FSA apresentou-se mais na cor amarela, pois o ângulo Hue obtido $(82,90)$ ficou mais próximo a $90^{\circ}$ (Tabela 2 ).

A umidade é um parâmetro de qualidade importante para os alimentos e está diretamente relacionada a incidência de água. Alimentos que possuem incidência elevada de água podem causar riscos à saúde dos consumidores, por criar um ambiente propício a proliferação de fungos e bactérias (Anvisa, 2018). A legislação brasileira não estabelece valor máximo de umidade para farinhas de hortaliças, no entanto, a RDC nº 263 estabelece que a umidade máxima em farinha, amido de cereais e farelo seja de 15\% (Brasil, 2005). Os valores de umidades obtidos nas FCA (7,95\%) e FSA (4,46\%) de Anjos et al. (2017); na FSA (6,72\%) de Severino et al. (2019) e na FSA (4,11\%) de Fortes et al. (2020), estão de acordo com a legislação vigente, indicando, que as farinhas de cascas e sementes de abóbora fornecem segurança alimentar adequada.

O teor de cinzas em alimentos fornece importantes informações sobre o valor nutricional em relação ao seu conteúdo em minerais (Martins et al., 2020). A legislação brasileira estabelece um limite máximo de $6 \%$ para o teor de cinzas em algumas farinhas vegetais (Brasil, 2005). O valor de cinzas da FCA de Anjos et al. (2017) determinado em mufla a $550^{\circ} \mathrm{C}$ (IAL, 2008) apresentou-se como o alimento de maior teor em minerais $(8,89 \%)$ quando comparada a sua FSA $(4,21 \%)$ e a FSA $(4,25 \%)$ de Severino et al. (2019), determinada pelo método da AOCS (2009) (Tabela 2). O valor superior de cinzas presente na FCA está relacionado a maior presença de minerais nas cascas de abóbora.

As fibras desempenham papel funcional nos organismos atuando na prevenção de doenças intestinais, no tratamento de obesidade e na redução dos casos de doenças cardiovasculares (Bock \& Conde, 2020). De acordo com a legislação, um alimento pode ser considerado de alto teor de fibras quando no produto existir no mínimo $6 \mathrm{~g} / 100 \mathrm{~g}$ de fibras (Brasil, 2012), desta forma os teores de fibras da FCA (16,36\%) e FSA $(20,31 \%)$ de Anjos et al. (2017) e FSA $(21,84 \%)$ de Fortes et al. (2020) estão dentro dos valores preconizados e podem ser consideradas como alimentos de alto teor de fibras (Tabela 2).

Quanto as proteínas, um alimento pode ser considerado de alto conteúdo de proteína quando possuir teor mínimo de 12\% (Brasil, 2012). Os teores de proteínas presentes na FSA (32,20\%) de Anjos et al. (2017) avaliada pelo método Kjeldahl clássico com fator de conversão do nitrogênio de 6,25 (IAL, 2008) e na FSA (33,94\%) de Severino et al. (2019) determinada pelo método Micro-Kjeldahl com fator de conversão do nitrogênio de 6,25 (AOAC, 2005) demonstram que a FSA se apresenta como alimento de alto teor de proteína quando comparada a FCA com 13,45\% de proteína de Anjos et al (2017) avaliada pela mesma metodologia que a FSA (IAL, 2008) (Tabela 2).

Os principais resultados bromatológicos das farinhas de resíduos de abóbora encontram-se na Tabela 2. 
Tabela 2. Principais resultados bromatológicos de farinhas contendo resíduos de abóbora (Cucurbita moschata) dos artigos científicos de língua portuguesa realizados no Brasil no período de 2011 a 2020.

\begin{tabular}{|c|c|c|c|c|c|c|c|}
\hline \multirow{2}{*}{ Parâmetros } & \multicolumn{3}{|c|}{ Anjos et al., 2017} & \multicolumn{2}{|c|}{ Severino et al., 2019} & \multicolumn{2}{|c|}{ Fortes et al., 2020} \\
\hline & FCA & FSA & Metodologia & FSA & Metodologia & FSA & Metodologia \\
\hline Umidade (\%) & 7,95 & 4,46 & IAL, 2008 & 6,72 & AOCS, 2009 & 4,11 & AOAC, 2012 \\
\hline Cinzas (\%) & 8,89 & 4,21 & IAL, 2008 & 4,26 & AOCS, 2009 & - & - \\
\hline Fibra bruta $(\%)$ & 16,36 & 20,31 & IAL, 2008 & - & - & - & - \\
\hline Fibra solúvel (\%) & - & - & - & - & - & 3,51 & AOAC, 2012 \\
\hline Fibra insolúvel (\%) & - & - & - & - & - & 21,84 & AOAC, 2012 \\
\hline Proteínas (\%) & 13,45 & 32,20 & IAL, 2008 & 33,94 & AOAC, 2005 & - & - \\
\hline Lipídios (\%) & 2,03 & 35,94 & IAL, 2008 & 35,82 & AOCS, 2009 & 33,13 & AOAC, 2012 \\
\hline Carboidratos (\%) & 67,68 & 23,18 & AOAC, 1997 & 19,26 & AOAC, 1997 & - & - \\
\hline Calorias (kcal/100g) & 347,18 & 520,70 & $\begin{array}{l}\text { Merril \& } \\
\text { Watt,1973 }\end{array}$ & 535,18 & $\begin{array}{c}\text { Merril \& } \\
\text { Watt, } 1973\end{array}$ & - & - \\
\hline $\begin{array}{l}\text { Fenólicos totais (mg de } \\
\text { equivalente de ácido gálico/g) }\end{array}$ & - & - & - & - & - & 963,11 & Lu et al, 2011 \\
\hline $\begin{array}{l}\text { Ativ. antioxidante ( } \mu \mathrm{mol} \text { de } \\
\text { equivalente de Trolox/g) }\end{array}$ & - & - & - & - & - & $14.970,33$ & $\begin{array}{l}\text { Ahn, Kim \& } \\
\text { Je, } 2014\end{array}$ \\
\hline PAOXI & - & - & - & - & - & 15,55 & $\begin{array}{l}\text { Vinson et al., } \\
1998\end{array}$ \\
\hline Ativ. de inibição de tripsina & - & - & - & - & - & ND & AACC, 1976 \\
\hline Valor $\mathbf{L}^{*}$ & - & - & - & - & - & 59,49 & Minolta, 1998 \\
\hline Valor $\mathbf{a}^{*}$ & - & - & - & - & - & 3,47 & Minolta, 1998 \\
\hline Valor $b^{*}$ & - & - & - & - & - & 27,83 & Minolta, 1998 \\
\hline $\operatorname{Croma}\left(C^{*}\right)$ & - & - & - & - & - & 28,04 & Minolta, 1998 \\
\hline Ângulo Hue & - & - & - & - & - & 82,90 & Minolta, 1998 \\
\hline
\end{tabular}

FCA: farinha de casca de abóbora; FSA: farinha de semente de abóbora e ND: não detectado. Fonte: Autores.

Quando comparados os percentuais de cinzas $(\mathrm{FCA}=8,89 \%$ e FSA $=4,21 \%$ e 4,26\%) e proteínas $(\mathrm{FCA}=13,45$ e FSA = 32,20 e 33,94) das farinhas de resíduos de abóbora de Anjos et al (2017) e Severino et al. (2019), respectivamente (Tabela 2) com os percentuais estipulados pela legislação (Brasil, 2005) para a farinha de trigo integral (teor máximo de cinzas de $2,5 \%$ e teor de proteína de $8 \%$ ), essas se mostraram, nutricionalmente, serem excelentes ingredientes substitutas do trigo em produtos de panificação e doces. 
Sendo a semente de abóbora uma oleaginosa rica em ácidos graxos como o palmítico, esteárico, oléico e linoléico (Pena et al., 2019), os valores de lipídios presentes na FSA (35,94\%) de Anjos et al. (2017) determinado com éter e extração direta em Soxhlet (IAL, 2008); os valores de lipídios na FSA (35,82\%) de Severino et al. (2019) obtidos por extração com éter de petróleo empregando o extrator Soxhlet (AOCS, 2009) e os valores de lipídios na FSA $(35,13 \%)$ de Fortes et al. (2020) determinada por extração com éter etílico em aparelho extrator do tipo Soxhlet (AOAC, 2012) (Tabela 2), mostram que a FSA possui percentual elevado de lipídios.

Em relação aos carboidratos e calorias, a FCA avaliada por Anjos et al. (2017) apresentou-se como a farinha de resíduo de abóbora com o maior valor de carboidratos (67,68\%) e menor valor calórico (347,18 kcal/100g) quando comparada à FSA (carboidratos $=23,18 \%$ e valor calórico $=520,70 \mathrm{kcal} / 100 \mathrm{~g}$ ) de Anjos et al. (2017) e a FSA (carboidratos $=19,26 \% \mathrm{e}$ valor calórico = 535,18 kcal/100g) de Severino et al. (2019), (Tabela 2). Segundo a RDC n 360, de 2003, do Ministério da Saúde (Brasil, 2003) o valor diário de referência (VDR) para carboidratos deve ser de até 300 gramas, portanto, a ingestão da farinha de casca de abóbora deve ocorrer de forma a se garantir uma dieta adequada em nutrientes e calorias, já que o consumo elevado de carboidratos pode desencadear dislipidemias e obesidade (Pereira, Formiga \& Coêlho, 2020).

Quanto as características terapêuticas, cabe destacar que, as sementes de abóbora possuem um componente chamado cucurbitacina (glicosídeo resinososo), que associado a alguns princípios ativos como os flavonoides, terpenos, saponinas e ácidos-p-hidroxibenzoico, desempenham atividade anti-helmíntica (Lima et al., 2020), porém, o alto teor de fibra insolúvel dos alimentos juntamente com outros fatores, tais como os antinutricionais (hemaglutininas, antitripisínico, ácido cianídrico, polifenóis e ácido oxálico), podem afetar a ação anti-helmíntica de farinhas de semente de abóbora (Bissacotti \& Londero, 2016).

A Tabela 3 contém os principais resultados terapêuticos das farinhas de resíduos de abóbora.

Tabela 3. Principais resultados terapêuticos de farinhas contendo resíduos de abóbora (Cucurbita moschata) dos artigos científicos de língua portuguesa realizados no Brasil no período de 2011 a 2020.

\section{Lima et al. (2020)}

\begin{tabular}{|c|c|c|}
\hline \multirow{2}{*}{ Parâmetro } & \multicolumn{2}{|c|}{ Doses de FSA } \\
\hline & $1 \mathrm{~g} / \mathrm{kg}$ & $3 \mathrm{~g} / \mathrm{kg}$ \\
\hline Anti-helmíntica & $\begin{array}{l}\text { Apresentou baixa eficácia no controle de } \\
\text { helmintos de equinos aos } 14,28 \text { e } 42 \text { dias } \\
\text { pós-tratamento e eficiência de } 74,6 \% \text { na } \\
\text { redução da contagem dos ovos aos } 14 \text { dias } \\
\text { pós-tratamento. }\end{array}$ & $\begin{array}{l}\text { Não apresentou eficácia e nem eficiência na } \\
\text { redução da infestação de helmintos de } \\
\text { equinos em nenhum dos períodos pós- } \\
\text { tratamentos avaliados. }\end{array}$ \\
\hline
\end{tabular}

FSA: farinha de semente de abóbora. Fonte: Autores.

Sendo a semente de abóbora (Cucurbita sp), um resíduo agrícola muito utilizado na culinária por possuir altos teores de proteína e ácidos graxos; além de possuir atividade antioxidante e atividade anti-helmíntica devido a presença do componente cucurbitacina, Lima et al. (2020) propuseram avaliar o efeito anti-helmíntico da FSA (Cucurbita moschata) em diferentes períodos pós-tratamento em equinos.

A ineficácia e ineficiência anti-helmíntica da dosagem de $3 \mathrm{~g} / \mathrm{kg}$ de FSA pode ser atribuída a complexidade que os equinos, animais não ruminantes, apresentam de digerir alimentos contendo alto teor de fibras insolúveis, que promoveram a aceleração da excreção do bolo fecal impedindo que as substâncias anti-helmínticas contidas na semente fossem liberadas (Lima et al., 2020). 


\section{Considerações Finais}

O uso da farinha de resíduos de abóbora como fonte funcional e nutricional é uma ótima alternativa para uso na alimentação, pela quantidade de lipídios, fibras, proteínas, minerais e agentes antioxidantes. Quanto ao seu uso como produto terapêutico, é indicado estudos para comprovar a sua eficácia científica.

Além das contribuições funcionais e nutricionais, o uso da farinha de resíduos de abóbora na alimentação humana e animal contribui no combate à fome, ao desperdício e reduz o impacto ambiental.

\section{Agradecimentos}

Ao Instituto Federal de Educação, Ciência e Tecnologia do Sul de Minas Gerais (IFSULDEMINAS) e ao Programa de Doutorado em Agricultura Sustentável da Universidade José do Rosário Vellano (UNIFENAS) pelo apoio técnico.

\section{Referências}

AACC (American Association of Cereal Chemists) (1976). Approved methods of the American Association of Cereal Chemists. (9a ed.), Saint Paul.

Agência Nacional de Vigilância Sanitária - ANVISA. (2018). Guia para determinação de prazos de validade de alimentos. Guia ${ }^{\circ} 16 / 2018$, versão 1. http://antigo.anvisa.gov.br/documents/10181/5056443/Guia+16_2018+prorrogacao+prazo.pdf/13a19f5f-94f8-4430-9548-6d43278ffb62.

Ahn, C. B., Kim, J. G. \& Je, J. I. (2014). Purification and antioxidant properties of octapeptide from salmon byproduct protein hydrolysate by gastrointestinal digestion. Food Chemistry, 147, 78-83. 10.1016/j.foodchem.2013.09.136.

Anjos, C. N., Barros, B. H. S., Silva, E. I. G., Mendes, M. L. M. \& Messias, C. M. B. O. (2017). Desenvolvimento e aceitação de pães sem glúten com farinhas de resíduos de abóbora (Cucurbita moschata). Arquivos de Ciências da Saúde, 24(4), 58-62. 10.17696/2318-3691.24.4.2017.870.

AOAC (Association of Official Agricultural Chemists) (2005). Official and Tentative Methods of the AOAC International. 18th Edition, Association of Official Agricultural Chemists, Maryland.

AOAC (Association of Official Analytical Chemists) (1997). Official Methods of Analysis. (16a ed.), Association of Official Analytical Chemists, Gaithersburg.

AOAC (Association of Official Analytical Chemists) (2012). Official Methods of Analysis. (16a ed.), Association of Official Analytical Chemists, Gaithersburg.

AOCS (American Oil Chemits' Societ) (2009). Official Methods and Recommended Practices of the American Oil Chemists' Society. (16a ed.), Champaing.

Araújo, K. T. A., Silva, R. M., Silva, R. C., Figueirêdo, R. M. F. \& Queiroz, A. J. M. (2017). Caracterização físico-química de farinhas de frutas tropicais. Revista Brasileira de Agrotecnologia, 7(2), 110-115.

Benítez, R. O. (2019). Perdas e desperdícios de alimentos na América Latina e no Caribe. Organização das Nações Unidas para a Alimentação e a Agricultura - FAO: http://www.fao.org/americas/noticias/ver/pt/c/239394/.

Bissacotti, A. P. \& Londero, P. M. G. (2016). Sementes de abóbora: prospecção para o consumo humano e utilização tecnológica. Disciplinarum Scientia, 17(1), 111-124.

Bock, F. M. \& Conde, S. R. (2020) Análise do teor de fibra em biscoitos, barra de cereais, pães e cereais matinais industrializados. Revista UNINGÁ, 57(3), 21-28. 10.46311/2318-0579.57.3.021-028.

Brasil. (2005). Ministério da Agricultura, Pecuária e Abastecimento - MAPA. Instrução Normativa ${ }^{\circ} 8$ de junho de 2005 . Regulamento Técnico de identidade e qualidade da farinha de trigo. Diário Oficial da União. Brasília, DF, 27 jun. 2005.

Brasil. (2003). Ministério da Saúde. Resolução RDC nº 360 de 23 de dezembro de 2003 da Agência Nacional de Vigilância Sanitária - ANVISA. Regulamento Técnico sobre Rotulagem Nutricional de Alimentos Embalados. Diário Oficial da União. Brasília, DF, 26 dez. 2003.

Brasil. (2005). Ministério da Saúde. Resolução RDC no 263 de 22 de setembro de 2005 da Agência Nacional de Vigilância Sanitária - ANVISA. Regulamento Técnico para produtos de cereais, amidos, farinhas e farelos. Diário Oficial da União. Brasília, DF, 23 set. 2005.

Brasil. (2012). Ministério da Saúde. Resolução RDC nº 54 de 12 de novembro de 2012 da Agência Nacional de Vigilância Sanitária - ANVISA. Regulamento Técnico sobre a informação nutricional complementar. Diário Oficial União. Brasília, DF, 13 nov. 2012.

Fioroto, C. K. S., Schuroff, H. P., Turchetto, Q., Emanuelli, I. P., Lizama, M. de los A. P. \& Gonçalves, J. E. (2019). Composição química de resíduos de alimentos como fonte alternativa de nutrientes: sustentabilidade aliado a promoção da saúde. Revista Valore, 4, 70-93. 
Fortes, R. R., Brigagão, T. C. S., Lourenço, C. O., Carvalho, E. E. N., Tavano, O. L., Garcia, J. A. D., Nachtigall, A. M. \& Boas, B. M. V. (2020). Caracterização física e química de farinha de arroz, farinhas de cascas de abacaxi e banana e farinha de semente de abóbora. Research, Society and Development, 9(9). 10.33448/rsd-v9i9.7293.

Instituto Adolfo Lutz. (2008). Métodos físico-químicos para análises de alimentos. (4a ed.), Instituto Adolfo Lutz - IAL, 1020 p.

Kim, M. Y., Kim, E. J., Kim, Y., Choi, C. \& Lee, B. (2012). Comparison of the chemical compositions and nutritive values of various pumpkin (Cucurbitaceae) species and parts. Nutrition Research and Practice, 6(1), 21-27. 10.4162/nrp.2012.6.1.21.

Lima, D. F. de, Brainer, M. M. de A., Fabino, R. F., Silva, B. C. da, Godoy, M. M. de, Fabino, R., Neto, \& Morgado, H. S. (2020). Potencial anti-helmíntico de semente de abóbora (Cucurbita moschata) em equinos. Brazilian Journal of Animal and Environmental Research, 3(3), 952-965. 10.34188/bjaerv3n3-016.

Lu, M., Yuan, B., Zeng, M., \& Chen, J. (2011). Antioxidant capacity and major phenolic compounds of spices commonly consumed in China. Food Research International, 44, 530- 536. 10.1016/j.foodres.2010.10.055.

Maldonade, I. R., Lozada, M. I. O., Amaro, G., Oliveira, L. de L. de, Luengo, R. de F. \& Machado, E. R. (2019). Propriedades funcionais e nutracêuticas de sementes de cucurbitáceas. Boletim de pesquisa e desenvolvimento 197. Embrapa Hortaliças, Brasília, DF. 22p. https://www.infoteca.cnptia.embrapa.br/infoteca/bitstream/doc/1114254/1/BPD197.pdf.

Martins, A. S., Pereira, S. R., Pereira, E. J. \& Freitas, R. F. (2020). Análise físico-química, microbiológica e sensorial de hambúrguer desenvolvido com fibra de jaca (Artocarpus heterophyllus), acrescido de inhame (Dioscorea sp.) e farinha de banana verde (Musa sp.). Research, Society and Development, 9(10). $10.33448 /$ rsd-v9i10.7542.

Matthewsa, K. K., O’Brien, D. J., Whitley, N. C., Burke, J. M. Miller, J. E. \& Barczewski, R. A. (2016). Investigation of possible pumpkin seeds and ginger effects on gastrointestinal nematode infection indicators in meat goat kids and lambs. Small Ruminant Research, 136. doi: 10.1016/j.smallrumres.2015.12.036.

Merril, A. L. \& Watt, B. K. (1973). Energy value of foods: basis and derivation, revised. Agriculture Handbook, ${ }^{\circ} 74$. Washington: United States Department of Agriculture, $105 \mathrm{p}$.

Minolta. (1998). Precise color communication: color control from perception to instrumentation. Tóquio: Konica Minolta.

Moher, D., Shamseer, L., Clarke, M., Ghersi, D., Liberati, A., Petticrew, M., Shekelle, P. \& Stewart. L. A. (2015). Preferred reporting items for systematic review and meta-analysis protocols. Systematic Reviews, 4(1). 10.1186/2046-4053-4-1.

Pena, M. G. dos R., Lima, T. A., Oliveira, M. A. L. de, Tavares, G. D., Costa, F. F. \& Chellini, P. R. (2019). Aproveitamento da semente de abóbora (Cucurbita moschata) no desenvolvimento de creme hidratante esfoliante. Biomedicina e Farmácia: Aproximações 2. Cap.7, 53-57. Ponta Grossa (PR): Atena Editora. 10.22533/at.ed.2311915047.

Pereira, A. de L., Formiga, W. A. M. \& Coêlho, A. M. M. (2020). Avaliação de calorias e macronutrientes dos cardápios de um restaurante universitário de uma instituição de ensino federal. Journal of Medicine and Health Promotion, 5(2), 59-69.

Severino, K. L. P., Crepaldi, J., Zequini, V. M., Monteiro, A. R., Pedro, M. A. M., Damy-Benedetti, P. de C., Cattelan, M. G. \& Veronezi, C.M. (2019). Potencial uso de sementes de abóbora (Curcubita moschata) como aproveitamento de resíduo. Revista Científica UNILAGO, 1(1).

Vale, C. P. do, Loquete, F. C. C., Zago, M. G., Chiella, P. V. \& Bernardi, D. M. (2019). Composição e propriedades da semente de abóbora. FAG Journal of Health, 1(4), 79-90. 10.35984./fjh.v1i4.95.

Vinson, J. A., Hao, Y., Su, X. \& Zubik, L. (1998). Phenol antioxidant quantity and quality in foods: vegetables. Journal of Agricultural and Food Chemistry, 46(9). 10.1021/jf980295o. 